\title{
De uma morada à outra: processos de re-coabitação entre as gerações*
}

\author{
Clarice Ehlers Peixoto** \\ Gleice Mattos Luz ${ }^{* * *}$
}

\begin{abstract}
Resumo
Desemprego, divórcio, viuvez, filhos que não saem nunca da casa dos pais são as razões que explicam porque, no Brasil, as gerações mais velhas coabitam cada vez mais com as mais jovens. Retornar para a casa familiar, ou ir morar na casa de um(a) filho(a) introduz uma nova dinâmica na organização doméstica: a reorganização do espaço - abrir, criar lugares para receber o novo(s) membro(s); a adaptação das regras, horários $e$ tarefas às necessidades $e$ atividades de cada um, e do grupo em particular. Morar com três ou quatro gerações implica em uma contribuição material $e$ financeira, mas, também, em um suporte moral e afetivo no apoio logístico do cotidiano doméstico. A vida em comum só é possível se existir este circuito de reciprocidades, senão a coabitação pode quebrar a harmonia familiar e tornar-se violenta.
\end{abstract}

Palauras-chave: Deslocamentos Habitacionais, Coabitação, Relações Intergeracionais.

\footnotetext{
* Recebido para publicação em maio de 2007, aceito em agosto de 2007. Os dados analisados neste artigo foram extraídos, basicamente, de pesquisas qualitativas sobre relações intergeracionais realizadas por C. Peixoto e da pesquisa de G. Luz "O Impacto do Desemprego nas Relações Familiares: Solidariedade e Conflito em Famílias de Camadas Médias", dissertação de Mestrado, PPCIS/UERJ, 2005.

*** Professora de Antropologia do Depto. de Ciências Sociais da UERJ. cpeixoto@uerj.br

**** Doutoranda do Programa de Pós-Graduação em Ciências Sociais da UERJ/PPCIS. gleicemattos@gmail.com
}

cadernos pagu (29), julho-dezembro de 2007:171-191. 
Processos de re-coabitação entre as gerações

From one Dwelling to Another:

Intergenerational Cohabitation Processes

\begin{abstract}
Unemployment, divorce, widowhood, children who never leave their parents' house, these are the reasons that explain why the older generations in Brazil cohabit with the younger generations more than before. Returning to one's parents' house, or moving to the children's house introduces a new dynamic into the domestic organization: the reorganization of space - the creation of places to receive new family members; the adaptation of rules, schedules and tasks, to the necessities and activities of each member and to the group's in particular. Living with three or four generations implies a material contribution as well as emotional and moral support for the logistics of daily domestic life. Living together is only possible when there is a circuit of reciprocities; otherwise, cohabitation can provoke violent rupture in the family's harmony.
\end{abstract}

Key Words: Habitational Displacements, Cohabitation, Intergenerational Relations. 
Crise econômica, desemprego e baixos salários atingem todos os setores profissionais e todas as idades, particularmente as gerações mais jovens, e repercutem diretamente na organização familiar, sobretudo, nas relações entre pais e filhos adultos.

Considerando que as políticas sociais brasileiras de apoio às famílias (Bolsa família, seguro desemprego, etc.) não são universais, $e$ as existentes são ainda precárias, cabe fundamentalmente à família desempenhar o papel de suporte central dos sujeitos (Peixoto e Bozon, 2001). Nesse sentido, o desemprego $e$ os baixos salários não são problemas exclusivamente individuais, posto que envolvem e afetam todo o grupo familiar. Dentre tantos outros problemas que acarretam, eles podem também provocar o retorno dos filhos (casados) à casa dos pais, e o suporte familiar sobre os efeitos do desemprego (e dos baixos salários) é fundamental para que os indivíduos possam superar esse período. Contudo, os filhos adultos consideram que "morar na casa dos pais é algo penoso de se viver" (Villeneuve-Gokalp apud Letrait, 2002). Os apoios materiais aos filhos adultos dependentes, e que vivem na casa dos pais, são percebidos por pais e filhos como um investimento para que possam alcançar posições melhores no mercado de trabalho.

$\mathrm{O}$ ir-e-vir entre a morada conjugal e a casa paterna (ou materna) não é um fenômeno muito recente. A novidade é o crescimento desta prática $e$ a sua amplitude, atingindo tanto os jovens das camadas populares quanto das camadas médias da sociedade brasileira. Isto porque, as gerações mais velhas foram favorecidas, em períodos anteriores de crescimento econômico, por programas governamentais de financiamento da casa própria, como o sistema do Banco Nacional de Habitação, cujas taxas de juros eram reguladas de acordo com os reajustes salariais. Com a extinção deste programa houve, de um lado, uma queda significativa na aquisição de imóveis pelas gerações mais jovens das camadas médias, como conseqüência das elevadas taxas de juros dos financiamentos privados $e$, de outro, a sua 
Processos de re-coabitação entre as gerações

inexeqüibilidade por parte das camadas populares (Peixoto, 2004:66).

Um outro fator deste deslocamento familiar e habitacional é o divórcio dos filhos; muitos retornam à casa dos pais face à redução da renda familiar e à impossibilidade de arcar com as despesas domésticas.

Desemprego, baixos salários e divórcio são, sem dúvida, as mais fortes razões da re-coabitação entre as gerações.

\section{Famílias ampliadas: quem se desloca para morar com quem?}

Existem duas modalidades de co-residência: a coabitação permanente e a re-coabitação (Attias-Donfut, 1995). No primeiro caso, estão pais e filhos(as) adultos (casados ou não) que nunca viveram separados $e$ as filhas (mães-solteiras com seus filhos) que sempre moraram com os pais. No segundo, inúmeros podem ser os fatores dessas mudanças de moradia, e a diversidade dessas situações de re-coabitação revela as implicações econômicas e sociais no interior do grupo familiar: mães que enviúvam $e$ passam a morar na casa de um(a) filho(a); mães divorciadas ou viúvas que acolhem seus filhos(as), também divorciados(as); pais ou mães que têm recursos reduzidos e, ainda assim, acolhem os filhos que atravessam um período de desemprego; pais que recebem aposentadoria reduzida (ou mães que recebem pensões precárias) e que vêm morar com os filhos em melhor situação econômica; pais ou mães mais abastados que não acolhem os(as) filhos(as) em suas casas, mas que ajudam financeiramente aqueles em dificuldade, casados ou não, etc.

\section{Morar na casa do(a) filho(a)}

As estatísticas ibegeanas indicam que $24,8 \%$ da população brasileira de mais de 60 anos moram com filhos ou parentes e que $37,9 \%$ vivem com os cônjuges, os filhos ou outros parentes (IBGE, 
2003). Em geral, nestas situações de coabitação intergeracional, o fato de ser proprietário da moradia determina quem acolhe quem.

A co-residência é mais freqüente no universo feminino entre as mulheres de mais idade, pois elas freqüentemente recorrem ao suporte moral dos filhos logo que enviúvam. Assim, ou elas vão morar com um dos seus filhos (se não são proprietárias) ou um dos filhos (em geral aquele que não é proprietário) retorna à casa materna, tanto para fazer companhia quanto para ajudar no cotidiano doméstico. Dona Maria viveu momentos de grande tristeza "depois da morte do meu marido, não conseguia viver sozinha. Então, fui viver com minha filha, meu genro e meus dois netos" (74 anos, telefonista aposentada, costura para fora para ajudar nas despesas da casa).

A coabitação pode ser lida, então, como um fator que estimula a solidariedade familiar nos períodos mais difíceis da vida de cada um de seus membros. Isso não significa, no entanto, que as trocas intergeracionais tenham aumentado ou diminuído e, sim, que as relações familiares adquiriram uma outra dinâmica, pois a re-coabitação sempre acarreta uma inversão dos papéis familiares: alguém perderá a autoridade (chefia) familiar, cedendo seu lugar para outro. Por exemplo, algumas mães viúvas perdem a autoridade doméstica quando acolhem um filho (ou filha) com dificuldade financeira, ainda que sejam as provedoras $e$ proprietárias do imóvel; às vezes, perdem até sua própria independência. Outras mães viúvas conseguem garantir a autoridade doméstica e, neste caso, o filho (ou filha) dependente perde a chefia da sua casa, mas nem sempre da sua família. Uma terceira possibilidade é quando a mãe viúva vai morar na casa de um filho (ou filha), tornando-se "visita", sem possibilidades de participar das decisões domésticas.

Essas situações de recoabitação atingem indiferentemente todas as camadas sociais, mas as mulheres que pertencem às camadas populares detêm mais indicadores negativos, sendo mais dependentes dos filhos: seus rendimentos são mais baixos posto que as atividades que desempenham são menos remuneradas que 
Processos de re-coabitação entre as gerações

as dos homens, sendo que algumas nunca trabalharam e recebem somente a pensão do marido morto. Além disso, elas têm os mais baixos níveis de escolaridade e são mais atingidas pela viuvez do que os homens. Após a viuvez, elas passam a viver mais freqüentemente com um filho(a), confirmando os indicadores sociais cujos índices mostram que as mulheres de mais idade, que não têm marido, vivem raramente sozinhas. Aliás, a concepção de que a solidão é um dos sentimentos mais presentes na viuvez feminina é reforçada pelo discurso de Dona Conceição, viúva há muitos anos e que "depois da morte do meu marido, eu não conseguia viver sozinha. Então, fui viver com minha filha, meu genro e meus dois netos" (74 anos, telefonista aposentada, costura para fora para ajudar nas despesas familiares).

Vale assinalar que, na impossibilidade de viver com um dos filhos, algumas dessas mulheres de idade procuram morar com um outro parente, por exemplo, uma irmã ou uma amiga que também vive sozinha. Em compensação, raros são os viúvos que vivem com os filhos. A maioria deles mora só por vontade própria e diz que viver com os filhos casados ou com parentes tolhe a sua liberdade e independência, perdendo, de certa maneira, o respeito e o prestígio que detinham outrora. Ou seja, a maioria dos homens viúvos ou separados prefere morar só ou se engajar em uma segunda união.

São muitas as trocas cotidianas para cumprir a agenda das tarefas domésticas e, sabemos, são as mulheres que geralmente se organizam em redes de ajuda. São elas, também, que mais se encarregam de cuidar dos membros dependentes: as crianças, os velhos e os doentes. Os homens, como assinalam Attias-Donfut, Segalen e Lapierre (2002:104), "são solidários, essencialmente, para os trabalhos manuais, bricolagens, pequenos reparos... formam uma rede técnica de ajuda". Assim, as mulheres idosas que vivem com seus filhos(as) casados(as) assumem várias tarefas domésticas, e mesmo o cuidado dos netos, para liberar a filha ou a nora para o trabalho. Dona Ruth relata que sua filha fez muita 
objeção a que ela se matriculasse na Universidade da Terceira Idade, pois ela

não quer que eu continue na UnATI porque ela trabalha muito e quer que eu ajude no trabalho de casa. Diz que não é para eu ter muitas atividades, senão vou ter um estresse! (74 anos).

A re-coabitação é, para Dona Ruth, sinônimo de controle da sua liberdade de escolha: morar com a filha significa, agora, duplicar a carga das tarefas domésticas, já que deve atender a sua família ampliada e abandonar seus interesses pessoais.

Nas famílias em que três gerações - avós, pais e netos passam a viver juntas, criam-se novos arranjos familiares para melhor administrar o cotidiano. Para Camarano (2003:7-8), eles

são uma forma importante de transferência e suporte entre gerações. (...) No momento de enxugamento do papel do Estado, observa-se que tem cabido às familias grande parte do cuidado com seus segmentos "dependentes". Esse cuidado se traduz em parte pela co-residência o que, em certas situações, beneficia as gerações mais novas e, em outras, as mais velhas (...) O fato de compartilhar o espaço físico possibilita o compartilhamento de renda, cuidados domésticos, das crianças, transporte, cuidados médicos, etc., ou seja, acredita-se que os arranjos familiares afetam e são afetados pelas condições de vida.

Contudo, o maior número de indivíduos vivendo na mesma casa não significa um aumento na renda familiar. Em pesquisa sobre o retorno dos aposentados ao trabalho (Peixoto, 2004), observamos que a reinserção no mercado formal ou informal é, para uns, conseqüência das baixas aposentadorias e do precário sistema de previdência social e, para outros, a oportunidade de preencher o vazio da inatividade. Mas, para a maioria dos aposentados entrevistados, a reinserção no trabalho tinha um 
Processos de re-coabitação entre as gerações

objetivo preciso: a solidariedade familiar. Ou seja, dar maior apoio financeiro aos filhos e netos:

os apoios se manifestam através de reciprocidades múltiplas: apoio econômico, apoio para o pagamento de aluguel, intervenções na vida cotidiana, ajuda no cuidado dos netos, sendo que muitos pagam os estudos e ajudam na manutenção (Id. ib.:81).

O relato de Dona Antônia é bastante ilustrativo sobre as transferências materiais de pais para os filhos (e netos). Diz ela:

Nunca parei a costura, pois a crise toca todo mundo. Minha aposentadoria é baixa e meu filho está desempregado, ele voltou para casa depois que se divorciou e não podia pagar aluguel e mais a pensão alimentar do filho dele. A gente tem que ajudar, pois ele sempre foi um bom filho. Ele já me ajudou muito e agora é a minha vez de fazer algo por ele (68 anos, viúva, locatária).

Uma outra situação, cada vez menos freqüente, é a dependência financeira dos filhos $e$ a possibilidade de manutenção da autonomia após a viuvez ${ }^{1}$, evitando a recoabitação. Dona Maria do Carmo (68 anos), por exemplo, mora só em um apartamento cedido pela filha, porque sua aposentadoria é muito baixa e não pode pagar um aluguel. Morar sozinha em imóvel dos filhos é uma rara possibilidade de manter a independência e, sobretudo, de impedir o acirramento dos conflitos geracionais, como diz Dona Maria do Carmo,

eu vivo completamente sozinha! E espero que ninguém venha aqui me atrapalhar. Bem, eles podem vir, mas sem demorar muito tempo, uma visita rápida. Eu tenho personalidade forte e sou muito independente.

${ }^{1}$ Sobre sociabilidade feminina na velhice, ver os estudos de Alda Britto da Motta, Flavia M. Motta e Clarice E. Peixoto. 
Observamos que alguns pais recebem ajuda de um(a) filho(a) ao mesmo tempo em que, por serem proprietários, acolhem em casa um(a) outro(a) filho(a) adulto(a) em dificuldade. É neste circuito de solidariedade familiar que se insere Dona Hercília e seus filhos, pois

duas das minhas filhas divorciadas estão desempregadas, então elas vivem na minha casa com seus filhos. Elas recebem a pensão alimentícia dos filhos, mas é muito pouco. Então, eu tenho que ajudar (...). Quanto aos meus filhos, um é dentista e o outro funcionário dos Correios e, quando estou precisando, eles me ajudam (60 anos, divorciada, manicure aposentada, continua trabalhando em salão de beleza).

\section{Retornar à casa dos pais: \\ readaptações às regras, aos ritmos $e$ ao espaço}

Muitas são as razões que levam os filhos a retornarem à casa dos pais, mas duas situações são mais determinantes: o desemprego e o divórcio. A re-coabitação ocasionada pelo desemprego dos filhos está associada à necessidade de manter condições de vida similares às anteriores e, principalmente, de garantir a sobrevivência daqueles que estão em dificuldade, pois os rearranjos familiares dependem "do contexto socioeconômico, de políticas sociais e não apenas de características individuais $e$ preferenciais" (Camarano, 1999:18). O impacto do desemprego altera também a contribuição de cada membro na composição da renda familiar e os rearranjos refletem o deslocamento das responsabilidades materiais. Nos momentos de crise é a família que se mobiliza para a superação dos problemas de cada um de seus membros. Desempregados, os filhos casados passam a depender novamente de seus pais, reinvertendo a ordem das ajudas e causando, muitas vezes, constrangimentos desagradáveis. coabitação

Por exemplo, Antônio (museólogo, 41 anos) diz que a re- 
Processos de re-coabitação entre as gerações

Foi um período curto, mas muito complicado. Eu sofria muito porque, principalmente, ficava na obrigação de homem de ter que sustentar a mulher. A gente não tem esses papéis, mas quem se sentia pior era eu porque ficava me sentindo impotente por constituir um casamento naquela situação financeira. Eu era o homem. Por mais que você não seja um homem tradicional - e eu não sou, não acho que tenha obrigação nenhuma de sustentar a mulher você se sente ruim à beça! Eu pensava: dependo da minha mãe pra morar junto. Eu me sentia mal no papel de provedor.

Ana Luzia (assistente de enfermagem, 33 anos) também viveu este desconforto, ainda que colaborasse em algumas despesas da casa materna, como o pagamento de luz e água. Ela tinha a sensação de que "estava ali de favor e tinha consciência de que estava dentro da casa da mãe dela". Os primeiros dois anos de convivência foram harmoniosos, até surgir a crise que separou o casal durante três meses. O motivo principal foi a falta de privacidade do casal, pois

a entrada para o quarto não era independente e todo o problema estava aí. Minha mãe, volta-e-meia batia na porta, que já era um problema porque era sanfonada, então ela pedia alguma coisa emprestada.

Diante da premência da re-coabitação, a família procura organizar a vida doméstica de forma a evitar tensões entre seus membros e manter a harmonia familiar. Retornar com sua própria família para a casa familiar introduz, em caráter provisório ou definitivo, uma nova dinâmica na organização doméstica tanto na distribuição do espaço, quanto do ritmo cotidiano. São espaços, regras, horários e tarefas que devem ser adaptadas às necessidades e atividades de cada um e do grupo em particular. A primeira medida é a reorganização do espaço: abrir, criar lugares para receber a nova família. Assim foi com Márcio, Patrícia e a 
filha pequena quando, desempregados, voltaram para o apartamento da mãe dele. Dona Lourdes morava com o marido, o enteado e o filho mais velho em um apartamento de três quartos e tiveram que redistribuir os quartos: o enteado foi para o quarto menor, o jovem casal $e$ a filha passaram a dividir o segundo quarto com o irmão mais velho de Márcio. Os conflitos entre irmãos, sogra e nora, cunhada e cunhado, marido e mulher gerados por essa nova situação familiar foram muitos $e$ por motivos diversos.

Dona Neusa (80 anos, aposentada) e seu marido também fizeram muitas adaptações no reduzido apartamento de quarto $e$ sala para receberem a filha Nair, o genro $e$ as duas netas. Transformaram o pequeno jardim de inverno, contíguo à sala, em um quarto para o casal, as netas pequenas foram dormir no quarto com eles. Aos poucos, Nair foi re-arrumando a casa e se desfazendo dos móveis e dos objetos de memória dos pais:

Lá era grande e tinha muita coisa. Aqui, minha mãe também tinha as coisas dela. Era tudo duplicado aqui em casa. Trouxe os móveis porque eu não pensava em ficar. Aí, aos pouquinhos, eu fui me desfazendo das coisas da mamãe porque os dela eram mais velhos. Também me desfiz de algumas coisas e fui mudando: tirei a cristaleira que ela tinha aqui, foi embora a cristaleira dela. Ficamos remanejando as coisas e, por final, a gente conseguiu botar os seis aqui dentro e ficou todo mundo acomodado. Do jeito que estava antigamente não dava pra colocar todo mundo aqui dentro não.

Uma vez reestruturado o espaço, Dona Neusa e o marido ficaram submetidos às novas normas e ritmos impostos pelas filha e netas; perderam a liberdade de circular em função da redução do espaço coletivo. Mais do que isso, as regras domésticas foram subvertidas, predominando a desorganização da casa, a "ditadura" das netas que não permitiam que a avó escutasse o rádio ou assistisse ao programa de televisão de sua preferência. 
Processos de re-coabitação entre as gerações

Conformada com a longa re-coabitação que já dura muitos anos, ela diz que "já não reclama de mais nada porque mãe é para isto mesmo".

Sabemos que a situação de desemprego afeta consideravelmente o consumo familiar; primeiro são os cortes nas despesas consideradas mais superficiais, em seguida, os cortes nas necessidades básicas. Para Nezosi (2000:7),

os orçamentos dos lares são reconsiderados em função da queda de renda. As despesas imprescindíveis [como aluguel], ocupam uma parte proporcionalmente muito mais importante, as arbitragens se fazem em detrimento das despesas julgadas menos necessárias. Apesar desses ajustes o desemprego permanece um período difícil. (...) Para além das famílias trabalhadoras, o desemprego é uma das razões maiores do sobreendividamento dos lares e, sobretudo, de seu empobrecimento.

Dona Marilza (vendedora, 54 anos) também viveu momentos de muita tensão quando sua filha Fabiana veio com o marido (ambos desempregados) e a neta morar com ela. Com remuneração muito baixa e a sobrecarga financeira, ela contraiu algumas dívidas para arcar com o aumento das despesas familiares. Hipertensa e com a saúde abalada ela vive aos sobressaltos:

Outro dia no trabalho, depois do telefonema de Fabiana [pedindo para comprar remédios para a neta], minha pressão foi nas alturas, quase desmaiei. Essa situação está sendo muito difícil para mim. Ando cansada e não consigo tranqüilidade com a vida da Fabiana desse jeito. Já era para eu ter me aposentado, mas o ticket [restaurante] e o vale-transporte vão fazer falta pra gente.

Assim, quando o(a) filho(a) dependente solicita aos pais apoios financeiro e moral para manter e educar seus próprios filhos, os pais-avós sabem que terão, muitas vezes, que assumir 
responsabilidades e tarefas que nem sempre desejam ou podem, como o cuidado dos netos. Cuidar dos netos é uma prática recorrente no Brasil, pois são poucas as creches e as escolas maternais da rede pública $e$ as do ensino fundamental funcionam somente meio período, obrigando os pais a lançar mão de sistemas informais de guarda das crianças, como seus pais aposentados. Este fenômeno é bastante comum nas camadas populares brasileiras, principalmente quando as filhas divorciadas (mas não só) retornam à casa dos pais porque seus salários são baixos, os aluguéis altos e as pensões alimentares versadas pelos ex-maridos são, também, baixas ou inexistentes. ${ }^{2}$ Nessas condições, é impossível, para as mães que trabalham, pagar alguém para cuidar dos filhos durante as horas de trabalho. São, então, as avós que ajudam os seus filhos/as, assumindo a tarefa de prover e educar os netos. É o caso da Dona Marieta, que já vive com uma filha solteira de 36 anos, mas que se prepara para acolher "a segunda filha que vem com seus três filhos morar comigo. Ela acaba de se divorciar e vai ficar aqui até que consiga se reequilibrar".

A necessidade da re-coabitação torna as relações intergeracionais mais densas e passíveis de tensões, pois com o retorno dos filhos casados à casa paterna ou materna os pais procuram participar ativamente na vida dos filhos, sobretudo, na dos netos. Além disso, o sentimento de pertencer ao universo doméstico da morada paternal não é mais o mesmo, posto que os filhos vieram de uma situação anterior de autonomia $e$ independência econômica.

Diferente da resignação de Dona Neusa e de Dona Lourdes, o pai de Juliana (28 anos, jornalista desempregada) decidiu não mudar o ritmo e as regras da casa quando sua filha veio, com o

2 Os processos judiciais são longos e seu custo nem sempre é acessível aos mais pobres. Além disto, há um alto índice de trabalho informal o que dificulta estabelecer uma prova e o valor da remuneração. 
Processos de re-coabitação entre as gerações

marido, morar temporariamente na casa dele. Para ela, o pai agia com certa

falta de respeito em não aceitar a vida que a gente escolheu. E, de repente tudo de novo ali, parecia que eu tinha 15 anos de novo, meu pai regulando cada passo meu, eu sem poder fazer nada: sem emprego, sem dinheiro $e$ sem teto.

Observamos, então, que os pais podem optar por exigir que as regras da casa sejam obedecidas ou procurar adaptá-las às necessidades de cada novo membro, muitas vezes em detrimento das suas. De todo modo, nessa nova situação de dependência dos filhos, a autonomia de cada um fica relativamente em suspenso e o sentido do apoio familiar é repleto de desconfortos de uns e outros.

Ainda que os laços familiares sejam fortes, as tensões criadas com a re-coabitação podem gerar rupturas entre pais $e$ filhos. No caso de Juliana e seu pai, a vida em comum se tornou insuportável e logo que o marido dela começou a trabalhar saíram, brigados, da casa paterna. O rompimento durou um ano $e$ meio $e$, apesar da reaproximação, o pai continuou interferindo na vida dela. Sarti (1995:46) afirma que a autonomia pressupõe respeito mútuo e, para isso, é preciso definir os "limites pessoais e a atenção às necessidades do outro. Respeitando-se os limites da autonomia, podem ser modificadas as relações de autoridade". É difícil saber respeitar os limites de uns e outros quando as fronteiras não são as mesmas para pais, avós e netos, posto que as visões de mundo, os valores e os comportamentos se modificam a cada geração.

Patrícia (mãe-nora) e Dona Lourdes (avó-sogra) vivem constantemente em conflito, porque possuem concepções divergentes sobre a educação de Eduarda (três anos). Enquanto esta critica a "inexperiência" da nora para cuidar da filha-neta, Patrícia rejeita os hábitos da sogra, 
porque ela tem um jeito completamente diferente do meu de educar. Eduarda está cheia de hábitos que eu não gosto. Tenho que ficar o tempo todo chamando atenção da Eduarda, porque eu falo uma coisa e minha sogra diz outra. Ela deseduca minha filha e isso é muito desgastante. Tenho que ficar calada porque aqui não é minha casa. A gente está aqui de favor e esse é o preço que eu pago. Se estivesse na minha casa não tinha que passar por isso.

Assim, mesmo que na trama cotidiana das relações familiares, as tensões geradas pela re-coabitação coloquem em risco o equilíbrio do grupo, o sistema de apoios - materiais e afetivos - entre as gerações procura manter a harmonia, pois "as trocas familiares são bilaterais, já que sempre se retribui o apoio recebido ainda que dificilmente se compense um serviço por outro do mesmo tipo" (Peixoto, 2005). São serviços e ajudas que podem variar na forma - restritas ou amplas, diretas ou indiretas, imediatas ou demoradas -, posto que as transferências públicas (auxílios) às famílias e indivíduos são ainda precárias ou inexistentes.

Pais e filhos continuam a se socorrer e a se sentir em dívida uns com os outros $e$ mesmo as situações de ruptura dos laços familiares não são barreiras para as transferências materiais quando um filho(a) está em dificuldade. Outros parentes, ou até mesmo os netos, desempenham o papel de intermediários entre pais e filhos.

\section{Tensões, violências, rupturas}

É difícil manter a boa distância quando se vive em uma família com duas, três ou mesmo quatro gerações. Existem tensões, conflitos $e$ até rupturas. $\mathrm{O}$ anseio por privacidade, a vontade de ter momentos solitários e "de escapar ao controle do grupo familiar para se refugiar em 'territórios pessoais"” (Beaujouan, 2000:58) são elementos que tensionam a harmonia familiar e pressionam a construção de estratégias para evitar os 
Processos de re-coabitação entre as gerações

conflitos ou a ruptura. Dona Lourdes, por exemplo, costuma passar muitos dias no seu sítio porque "precisa descansar um pouco a cabeça", já que ela tem constantes atritos com a nora, Patrícia, e tenta mediar aqueles entre os seus filhos. Os ressentimentos pela falta de privacidade de uns e de outros se transformam, freqüentemente, em discussões acirradas. Sua nora Patrícia faz do curso de cabeleireiro um refúgio para "se desligar de todos os problemas" e dos conflitos com a sogra.

Não restam dúvidas de que a maioria dos jovens casais sonha em ter sua própria morada, não só para fugir das pressões e dos conflitos cotidianos, mas, principalmente, para reconstruir a vida conjugal sem interferências e querelas. Assim, Juliana e seu marido, tão logo conseguiram meios para alugar um apartamento, se mudaram mesmo sem os móveis porque, diz ela, "a gente chegou bem perto de explodir". Não romperam antes porque dependiam financeiramente do pai dela, mas o fizeram assim que conquistaram autonomia. Se Ana Luzia e Marcelo estão separados pela segunda vez, mas na expectativa de viver juntos novamente "nossa relação vai melhorar se a gente voltar a ter nossa casa" -, Antônio diz que só não se separou porque era a fase inicial do casamento, mas,

se esse tipo de conflito [entre a mulher e a mãe] acontece num casamento que já tem dez anos pode até levar ao fim da relação (...) eu tinha a consciência de que tinha que ter minha casa (...) sorte que a relação conseguiu se manter.

A interferência dos pais nos problemas conjugais dos filhos e dos avós na educação dos netos, as questões de ordem prática que giram em torno do espaço doméstico, como a organização da casa, a escolha dos programas de rádio ou televisão, o uso do telefone, os amigos dos netos e, principalmente, a necessidade de privacidade dos casais são fatores que interferem no cotidiano das famílias que re-coabitam, acionando tensões entre seus membros. Estas podem se transformar em maus-tratos e até em violência 
física, como assinala Jaspard (2000:12),

\begin{abstract}
as violências contra as pessoas são, freqüentemente, institucionais uma vez que estão ligadas as regras de funcionamento das instituições nas quais se apóia a sociedade: a família, a escola, o trabalho, o sistema de proteção social, de saúde, assistência pública... Elas são igualmente sociais posto que dependem das condições de vida, do meio em que vivem, da posição na hierarquia social, das categorias de idade e dos sexos.
\end{abstract}

As pesquisas brasileiras sobre violência familiar têm se detido mais nos maus-tratos contra mulheres e crianças, deixando de lado a violência contra pessoas de mais idade. Os poucos estudos sobre este segmento etário ${ }^{3}$ mostram que o agressor é sempre um membro da família, em geral, um filho(a) ou enteado(a). Observamos, então, que os abusos, as negligências e os maus-tratos são mais recorrentes nas situações de coabitação entre gerações, agravadas pelas dificuldades financeiras que levam as famílias a dividirem moradias com espaços exíguos. A falta de espaço físico inviabiliza a privacidade de cada um. Dividir o quarto, dormir na sala ou mesmo no quarto de serviço são situações freqüentemente encontradas nas famílias brasileiras, principalmente as de menor poder aquisitivo.

Ou seja, as relações familiares não são regidas somente pela harmonia das relações de troca. Os conflitos entre as gerações, conseqüência das relações de autoridade e de poder entre pais, filhos e netos, são inerentes à realidade familiar, uma vez que ela é atravessada por sentimentos contraditórios como amor e ódio, generosidade e avareza, solicitude e descaso.

3 Os trabalhos de Pasionato, Camarano e Machado (2004), Minayo (2003), Debert (2003), Alves (2001) são referências importantes no estudo da violência contra velhos. Peixoto desenvolve, atualmente, uma pesquisa sobre a violência doméstica e institucional contra pessoas de mais idade. 
Processos de re-coabitação entre as gerações

\section{Considerações finais}

As questões provocadas pela re-coabitação, que envolvem relações intergeracionais, revelam que, mesmo diante de tensões internas, a família possui uma dinâmica intensa na qual seus integrantes são continuamente chamados a reestruturar estratégias de sobrevivência e de convivência para que o grupo familiar não se desintegre. Nesse sentido, os elementos da solidariedade constituem
a base da redistribuição intrafamiliar dos apoios dispensados por uns e outros, morando ou não juntos. [Esta] se dá num circuito de reciprocidade [onde] a vida cotidiana só é possível através das trocas entre os membros da família (Peixoto, 2005:238).

Os filhos acreditam que têm o dever de retribuir as múltiplas ajudas que recebem dos pais. Como nem sempre podem contribuir para as despesas da casa, procuram colaborar nas tarefas domésticas, resolver questões bancárias e burocráticas, acompanhar os pais (e/ou avós) ao médico e outros pequenos serviços $e$ apoios. Essas práticas são consideradas como um contra-dom, ou seja, uma forma de reconhecer a dádiva, agora transformada em dívida (Peixoto, 2004). Isto porque os filhos acreditam que, uma vez que constituíram sua própria família, seus pais já não são obrigados a sustentá-los.

Do ponto de vista dos pais, o sentimento da "obrigação" de ajudar os filhos em qualquer circunstância é praticamente eterno. Impossível não atender as solicitações de um(a) filho(a) necessitado(a), pois "a família é o mais importante, penso que a família é tudo na vida!", como diz Dona Yolanda. Essa obrigação requer, igualmente, uma retribuição. Por exemplo, o Sr. Luis (biólogo, 54 anos), que acolheu a filha Juliana e seu marido quando estavam desempregados, se ressentia porque eles raramente participavam das refeições, desrespeitando a regra do encontro familiar em volta da mesa. Dona Marilza (vendedora, 54 
anos) solicita sistematicamente o apoio do genro nas "tarefas masculinas", como os serviços de encanamento e eletricidade. Dona Neusa (aposentada, 80 anos) sempre pede para filha acompanhá-la nas consultas médicas e para a neta mais velha pagar algumas de suas contas. Dona Lourdes (aposentada, 52 anos) demanda à nora Patrícia que cuide da casa e da família sempre que ela viaja para o sítio.

É interessante apontar para a distinção proposta por Singly entre: a) pais \& filhos que "doam" sem receber, o que ele chama de "doador exclusivo"; b) aqueles que só recebem: o "recebedor exclusivo"; c) e as relações familiares nas quais existe um duplo fluxo ("doador" e "recebedor"). O autor afirma que, para os pais, dar sem receber é melhor percebido do que receber sem dar nada aos filhos. Os pais não querem ser dependentes e muito menos um peso para os filhos. Quanto aos filhos, o sentimento de obrigação para com os pais idosos ainda é grande. Assim, "a qualidade (a vivência) das relações intergeracionais é compatível com o sentimento do dever, e mesmo a obrigação, mas não com o sentimento de dependência" (Singly, 2007:115).

Em suma, os deslocamentos de uma morada à outra é um fenômeno banal nas famílias brasileiras, cada vez mais pressionadas pelas dificuldades financeiras de uns e de outros. Diante deste cenário, a coabitação, mesmo que indesejada, é parte da solidariedade intergeracional e implica em novas formas de organização do espaço doméstico e de adaptação à vida em comum para a preservação da harmonia familiar. 
Processos de re-coabitação entre as gerações

\section{Referências bibliográficas}

Alves, Andréa Moraes. A Construção social da violência contra os idosos. Textos sobre Envelhecimento, ano 3, nº 6, Unati/UERJ, 2001, pp.9-31.

Attias-Donfut, Claudine; Segalen, Martine e LapierRe, Nicole. Le nouvel esprit de famille. Paris, Odile Jacob, 2002.

ATtiAs-Donfut, C. Transferts publics et transferts privés entre générations. In: ATTIAS-DONFUT, C. (org.) Les Solidarités entre Générations: Vieillesse, Familles, État. Paris, Nathan, 1995.

BEaujouan, Cécile. Tempo familiar e tempo individual entre desempregados. In: PEIXOTO, Clarice, SINGLY, François e CicCHELLI, Vincenzo. (orgs.) Família e Individualização. Rio de Janeiro, FGV, 2000.

CAmarano, Ana Amélia e GhaOuRI, Solange K. Família com Idosos: Ninhos Vazios? Texto para Discussão, no 950, IPEA, 2003.

CAmarano, Ana Amélia. Muito Além dos 60: os novos idosos brasileiros. Rio de Janeiro, IPEA, 1999.

DEBERT, Guita Grin. Jornal da Unicamp, 4-10 de agosto de 2003.

IBGE. Indicadores Sociais, 2003.

JASPARD, Maryse. Violence et maltraitance? Le poids des mots et des chiffres. Gérontologie et Société, n 92, 2000, pp.11-28.

LETRAIT, M. L'utilisation par les chômeurs du temps libéré par l'absence d'emploi. Économie et Statistique, nºs 352-353, Paris, 2002.

MINAYO, Maria Cecília. Violência contra idosos: relevância para um velho problema. Cadernos de Saúde Pública 19(3), Rio de Janeiro, maijun, 2003, pp.783-791.

NEZOSI, Gilles. Quelques éclairages sur les conséquences du chômage sur la famille. Recherches et Prévisions - Chômage et famille, $\mathrm{n}^{\circ}$ 60, Paris, CNAF, 2000.

Pasionato, Maria Tereza; Camarano, Ana Amélia; Machado, Laura. Idosos Vítimas de Maus-Tratos Domésticos: Estudo Exploratório das Informações dos Serviços de Denúncia. Trabalho apresentado no XIV 
Encontro Nacional de Estudos Populacionais, ABEP, Caxambú (MG), setembro de 2004.

PEIXOTO, Clarice. Solidariedade familiar intergeracional. In: ARAÚJO, Clara e SCALON, Celi. Gênero, família e trabalho no Brasil. Rio de Janeiro, FGV, 2005, pp.225-240.

PEIXOTO, Clarice. Aposentadoria: retorno ao trabalho e solidariedade familiar. In: PEIXOTO, Clarice. (org.) Família e Envelhecimento. Rio de Janeiro, ed. FGV, 2004.

PEIXOTO, Clarice e BOZON, Michel. Comportamentos Familiares: resultados e perspectivas. Interseções: Revista de Estudos Interdisciplinares, $\mathrm{n}^{\circ} 2$, dossiê Análises Contemporâneas sobre os Comportamentos Familiares, Rio de Janeiro, UERJ, 2001.

SARTI, Cynthia A. Família e Individualidade: um problema moderno. In: Carvalho, Maria do Carmo B. (org.) A Família Contemporânea em Debate. São Paulo, EDUC, 1995.

SINGLY, François de. Sociologia da família contemporânea. Rio de Janeiro, FGV, 2007. 